\section{Appetite for destruction}

Californians worried about unemployment and social unrest can always find solace in drink. But the news is no rosier here: a new strain of the vine-loving louse phylloxera (Dactulosphaira vitifoli$a e$ ) is munching its way through hitherto resistant rootstocks.

Phylloxera is native to North America east of the Rocky Mountains, and has been living in native vines since time immemorial. It turned up in Europe in the 1860 s and laid vineyards to waste until growers learned how to graft vines onto pestresistant rootstocks. It was found in California at about the same time, in vineyards that grew imported European varieties. The Californian wine industry was then in its infancy.

A rootstock called AXR\#1 was found to be especially resistant. Researchers at the University of California, with the cooperation of local growers, planted AXR\#1 in 1903 and continued trials of AXR\#1 until 1958, without noticeable loss of phylloxera resistance. This is remarkable, considering that the resistance of AXR\#1 grown in Europe in the 1870 s wore off during the First World War.

But at more than 70 years old, never a whisper of trouble, the continued health of AXR\#1 seemed too good to last. In 1982, Jeffrey Granett, professor of entomology at UC Davis, and his colleagues found a strain of phylloxera in Napa and Sonoma counties, the heartland of the California wine region, that lived quite happily on AXR\#1 roots. The new strain was dubbed Biotype B, to distinguish it from the the more familiar kind (now Biotype A) found throughout Californian vineyards, but which AXR\#1-grown vines resist. Biotype B has now been found in six counties.

Overheated comparisons between phylloxera and AIDS, though, are wide of the mark. Rootstocks resistant to Biotype B are known. All that growers need to do is replace their current vines - at a price. "The estimated losses are upwards of $\$ 1$ billion for Napa and Sonoma counties, just [because of] Biotype B", says Granett. "Roughly 50,000 acres are at risk in those two counties." The costs are incurred not only in replanting but in the five years of lost production needed for the new vines to become established.

Apart from pulling up the vines and

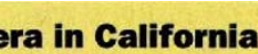

starting again, there is not, as yet, a practical way of exterminating phylloxera. The best strategy, says Linda Bisson, professor of viticulture and oenology at UC Davis, is one of "peaceful coexistence"

Those with an aggravated sense of the biblical might interpret the advent of Biotype B as just desserts for an industry unwilling to heed advice from (or invest in) UC Davis, the research arm created to foster it. Bisson and Granett may be forgiven for feeling like unwelcome Cas-

Counties

1. Mendocino

(2) Lake

(3) Sonoma

(4) Napa

(5) San Joaquin

(6) Alameda

(7) Santa Clara

Vital signs

"WE would like to look at the molecular evolution of the Solar System. This is now the new mission - how life evolved on Earth. Studying the Solar System is the link between the cosmos, and the formation of the elements, and the molecular evolution of life as it formed on Earth." So says Moustafa Chahine, chief scientist of the NASA Jet Propulsion Laboratory (JPL) in Pasadena in the hills above Los Angeles. This visionary view provides the thread that connects JPL's current suite of missions.

JPL has had spectacular successes, most notably with the Voyager missions, but the space race is over, and it has been forced to adopt a leaner image. One small mission, currently under study, typifies the new JPL philosophy - a rapid fly-by of Pluto. The entire science package would have a mass of less than $5 \mathrm{~kg}$, and JPL scientists are working on ways to make ultra-miniature instruments for the purpose. The CCD camera, for example, will tip the scales at less than 200 grams.

Smallness is a part of other projects, too. Each one of a projected series of robot Mars rovers will fit inside a shoebox. A robot weather station designed for the surface of Mars will have a mass of less than 50 grams.

Such devices represent engineering achievement, but overt science has come to JPL surprisingly recently. In 1978, Chahine, then an engineer working on fluid dynamics, was asked to set up JPL's Science Division, with a task of introducing scientific objectives in on the ground floor of mission design.

Science is in the forefront in JPL's current crop of projects. Magellan has completed the mapping of Venus by radar; Galileo (for all its problems) is on course for Jupiter, and will release a probe into its atmosphere; the Mars Observer (effectively a weather satellite for the red planet) will be JPL's first look at Mars since the Viking missions 17 years ago; the miniature Mars rovers will add the complementary worm's-eye view; and the still-to-be-launched Cassini mission will take another look at Saturn and probe the murky atmosphere of its moon Titan.

JPL is also involved in SETI, the Search for Extraterrestrial Intelligence. Not forgetting the evolving Mission to Planet Earth, which has a more focused objective than it once did, namely to firm up the uncertainties in the global climate system (such as the role of clouds) that are a brake on fuller understanding of global climate change. Taken together, the goal is to establish the physical conditions necessary for life on Earth and elsewhere in the Universe. 